Journal of Al Azhar University Engineering Sector

Vol. 12, No. 45, October, 2017, 1351-1358

\title{
OPTIMAL DG PLACEMENT IN A RADIAL DISTRIBUTION NETWORK FOR RELIABILITY IMPROVEMENT
}

\author{
I. A. Sultan, R. A. Swief and M. M. Mostafa \\ Electrical Power and Machines Department, Faculty of Engineering, Ain Shams \\ University, Cairo, Egypt
}

\begin{abstract}
This paper presents an efficient Grey Wolf Optimization technique to improve the reliability of distribution systems. Various reliability objectives such as energy not supplied, System Average interruption Frequency Index and System Average Interruption Duration Index are solved using the Grey Wolf Optimization method for optimal placement of distributed generators in radial feeders for reliability enhancement. Distributed generation sources are becoming more prominent in distribution systems due to the incremental demands for electrical energy and sometimes provide the lowest cost solution to handling low-voltage or overload problems. Siting and sizing of Distributed generation sources have profoundly impacted on the system losses in a distribution network. Assessment of customer power supply reliability is an important part of distribution system operation and planning. Distribution system reliability assessment is able to predict the interruption profile of a distribution system based on system topology and component reliability data. Distributed generation is being adopted in distribution networks with one of the objectives being enhancement of system reliability. Grey Wolf Optimization technique is proposed to obtain the optimal location DG to improve the reliability. The effectiveness of the proposed objective functions has been investigated on standard test distribution systems (69 bus radial distribution systems).
\end{abstract}

KEYWORDS: Distributed Generator (Dg), Optimal Location, Power System Reliability, Grey Wolf Optimization, Reliability Improvement.

\section{INTRODUCTION}

DUE TO the rapid increase in the demand for electricity, environmental constraints, and the competitive energy market scenario, the transmission and distribution systems are often being operated under heavily loaded conditions. In the earlier days, evaluation of the adequacy of the generation system and reliability of the transmission system were among major studies in the system planning. The recent experiences from blackouts indicate that, in many cases, the triggering events for such widespread failures took place in the distribution level. Statistically,

the majority of the service interruptions to the customers come from the distribution systems. Detailed reliability evaluation of the distribution system has, therefore, become very important in the planning and operating stage of a power system. The artificial intelligence-based methodologies, such as the use of fuzzy variables, genetic algorithm, simulated annealing, ant colony systems, and other evolutionary techniques have 
increasingly been used for the distribution system optimization problem [1],[2], [3],[4]. Two clear advantages of these methods are the avoidance of local minima, if any, and better handling of multiple objectives and constraints that are not always easy to formulate in a conventional optimization problem. The objective of a reliability-driven design of a distribution system is to reduce the frequency and duration of power interruptions to the customers. This will indicate the reduction in the number of customers affected by individual faults, reduction in the time needed to know the location and isolate a fault, thereby, reduces the time required to restore power to the affected customers, and strengthening of the power network by improving the existing power lines and installing new power lines and equipment, if required. In recent years, there has been some works reported on addressing the reliability issues. The majority of these works use computational intelligence-based methods to maximize the reliability of the system. The energy not supplied (ENS), system average interruption duration index (SAIDI) and system average interruption frequency index (SAIFI) are some of the widely used reliability indices in these approaches [5]. The failure history of the component is utilized to compute the failure rates.The Grey Wolf Optimization (GWO) technique is used to maximize the reliability at the load points in the system. A reliability evaluation can be used is the DG penetration which provides the most optimum solution. Then what is the best location in the system to add the DG? Many DGs are currently placed in or near the substation, probably due to convenience of installation. However, locating DGs further out on the circuit can lead to improvements in losses, reliability, or both. Applying DGs to a distribution system contribute to improve system reliability. So maximizing reliability can also be a criterion for seeking optimal DG location. This paper presents a reliability analysis based on set theory and discusses how the system load and additional generation (provided by DG) affect the system reliability.

First of all reliability calculation is obtained from [5], [6] and its improvement appears in [7]. A methodology is proposed in [8] for the optimal siting of distributed generators a security and reliability constrained distribution network can accept, In [1] an ant colony system algorithm is used to derive the optimal DG placement scheme for radial distribution networks. IN [3] a multiobjective optimization methodology (ant colony) to optimally place switches and protective devices in electric power distribution networks., IN [9], the authors firstly present The radial distribution feeder protection strategy without consideration for distributed generation (DG). Then, the addition of DG across the feeder (constrained in terms of power and/or energy capacity) is introduced in the model. [10] Proposes differential search (DS) algorithm to solve distribution system reliability optimization problem. In [11] two criteria discussed for the optimal placement of a DG for time-varying loads. One is to maximize the reliability improvement, and the other is to minimize the power loss in the system. To improve system reliability for radial distribution systems (RDS) with distributed generation (DG) under fault conditions, switch placement schemes are proposed in [12] to form self-supported areas after fault isolation. Customer priority is also considered in this problem. The switch placement problem is formulated as a nondifferentiable, multiobjective optimization problem. the authors in [4] aim to study the effect of DG on reliability of distribution system. And in [13] aim to study the impact of different locations of DG on reliability of distribution system. In [2] few complex reliability optimization problems are solved by using a very recent nature-inspired metaheuristic called gray wolf optimizer (GWO) algorithm. 69 bus data can be found in [14],[15],[16]

Section II gives an overview of the probabilistic reliability assessment technique used in this paper. Section III provides an overview for the proposed test system used. A description of DG operation and its impact in Section IV. DG penetration with grey wolf optimization case study and its results in Section V, and Section VI concludes this paper. 


\section{RELIABILITY}

The proposed model analyses the impact of predictive branch failures, a fundamental element to assure the continuity of service to customers. If a branch suffers an unexpected event, i.e., a fault or an open circuit, this can lead to a blackout state to the RDS, which is caused by the interruption of the power supply for a portion of the network.

\section{A. RELIABILITY INDEXES}

The three basic customer related indices for reliability analysis of distribution system are: rate (or frequency) of failure $\lambda_{s}$, average outage time (or average duration of failure) $r_{s}$ and average annual outage time $U_{\mathrm{s}}$ [3]. $\lambda_{\mathrm{s}}=\Sigma \lambda_{\mathrm{i}}, \mathrm{U}_{\mathrm{s}}=\Sigma \lambda_{\mathrm{i}} \mathrm{r}_{\mathrm{i}}, \quad \mathrm{r}_{\mathrm{s}}=\mathrm{U}_{\mathrm{s}} / \lambda_{\mathrm{s}}$ where $\lambda_{\mathrm{i}}$ is the failure rate of load point $i$ and $r_{i}$ is the average outage time of load point $i$. Although the three primary indices are fundamentally important, they do not always give a complete representation of the system behaviour and response. For instance, the same indices would be evaluated irrespective of whether one customer or 100 customers were connected to the load point or whether the average load at a load point was $10 \mathrm{~kW}$ or 100 MW. In order to reflect the severity or significance of a system outage, additional reliability indices can be and frequently are evaluated. The additional indices that are most commonly used are defined in the following sections.

1-System Average interruption Frequency Index (SAIFI)

$\mathrm{SAIFI}=\sum \lambda \mathrm{iNi} / \sum \mathrm{Ni}$

2-System Average Interruption Duration Index (SAIDI)

$\mathrm{SAIDI}=\sum \mathrm{UiNi} / \sum \mathrm{Ni}$

3-Customer Average Interruption Duration Index (CAIDI)

$\mathrm{CAIDI}=\sum \mathrm{UiNi} / \sum \lambda \mathrm{iNi}$

4-Customer Average Interruption Frequency Index (CAIFI)

CAIFI $=$ Total no of customer interruption/Total no of customer affected

5-Average Service Availability Index (ASAI)

$\mathrm{ASAI}=\left(\sum \mathrm{Ni} * 8760-\sum \mathrm{UiNi}\right) / \sum \mathrm{Ni} * 8760$

6-Average Service Unavailability Index (ASUI)

ASUI $=1-A S A I$

7-Energy Not Supplied (ENS)

$\mathrm{ENS}=\sum \mathrm{La}(\mathrm{i}) \mathrm{Ui}$

8-Average Energy Not Supplied (AENS):

$\mathrm{AENS}=\left(\sum \mathrm{La}(\mathrm{i}) \mathrm{Ui}\right) / \sum \mathrm{Ni}$

Here, Ni is the no of customers at load point $\mathrm{i}, \mathrm{Ui}$ is the annual outage time at load point $\mathrm{i}$.

B. RELIABILITY EVALUATION

There are many reliability indices used to evaluate a RDS. The most common indices used by electric utilities are system average interruption frequency index (SAIFI) and system average interruption duration index (SAIDI)[8],[9],[11],[3],[7],[1]. However, in order to reflect the severity of a system outage, additional reliability indices can be evaluated, like the energy-not-supplied index (ENS) and average energy-not-supplied index (AENS) [10],[7]. For the purpose of optimization, we will use (ENS). Only long interruptions are considered to determine the ENS, i.e., short and transient interruptions are not included. In most European countries, an interruption is referred to as a short interruption if it last 3 minutes or less. A long interruption is an interruption that lasts more than 3 minutes.

\section{69-BUS TEST SYSTEM}

This system consists of 69 nodes, 8-lateral radial distribution system, 69 sectionalizing and 5 tie-switches as shown in figure 1. The initial configuration has open lines 70, 71, 72,73 and 74 . The nominal active and reactive load on the system is $3.8015 \mathrm{MW}$ and 2.6946MVAR, base Voltage is $12.66 \mathrm{kV}$. Load flow data of the system are obtained from 
[14]. The upper and lower limits of voltage magnitude for the load points are considered $1: 05^{\text {p.u. }}$ and $0: 95^{\text {p.u. }}$, respectively. Furthermore, the limits of line capacity are taken from [15]. The reliability parameters are from the RBTS-BUS2 [6]. This system has 48 load points. For this system, large user, industrial, commercial, agriculture, residential, government and institutions and, office and buildings are considered. The customer data, with few modifications is obtained from RBTS-BUS4 [6].

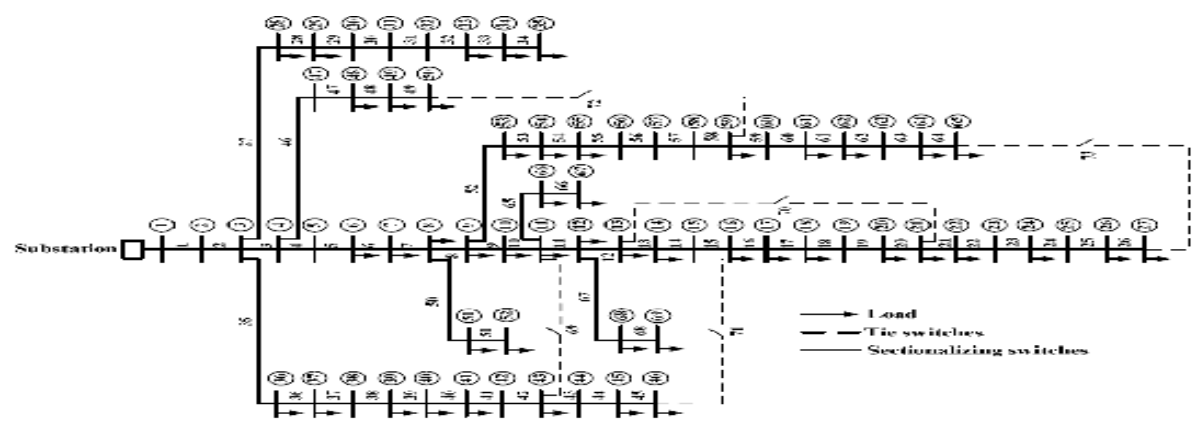

Fig. 1. Tested 69 bus radial distribution system.

\section{DISTRIBUTED GENERATION}

The utilities evaluate different approaches to provide competitive rates and acceptable reliability levels to customers. DG consists of small generators typically ranging in capacity from several kilowatts to $10 \mathrm{MW}$ connected to distribution systems. The high cost associated with the power interruptions and considering that the costs of transmission and distribution systems are taking an increasingly large portion of the utility capital investment, use of DG in power industry could be a cost effective solution to enhance system reliability. When a fault occurs in the distribution system, by opening switches in the upstream and downstream side of DGs, an isolated area can be supplied. In other words, DGs can improve reliability through islanding operation. Furthermore, DGs can operate as on-site or backup units.

\section{A. DG OPERATION}

If a system has a DG, there are at least three ways to operate the DG when a circuit outage occurs:

-The first way is to disconnect the DG from the system. In this case, the DG is not brought back online until the outage is cleared. Thus, during the outage, the DG will not benefit either the adjacent circuits or the circuit to which it is attached. Applying a DG to a circuit that fails frequently limits the reliability contribution of the DG. Therefore, if an improvement in overall system reliability is the goal and DGs may be used to support adjacent circuit problems, a DG that is disconnected during contingencies should be located in the circuit that is least likely to fail.

-The second way to operate a DG is in island mode. After the fault is isolated, if the DG is in the part of the system that is not affected by the failure, the DG can remain in service. As shown in Fig. 2, if a fault at point A is isolated by openings SW1 and SW2, the DG may supply power downstream of SW2. In this case, the DG should have sufficient capacity to satisfy that proportion of the system load. This paper does not consider islanding.

-With the third mode of operation, the fault is isolated and the DG is tripped. Next, customers not in the faulted area and/or the DG are switched to an adjacent circuit. The DG is then put into service to support the alternate feed. As indicated in Fig. 3, after a failure at point $\mathrm{A}$ is isolated, the tie switch can be closed, so that the customers between SW1 and the tie switch can be fed by circuit S1, or assume a failure at point B occurs. In this case, SW3 and SW2 are opened, and the tie switch and SW4 are closed to allow the 
adjacent circuit S0 to feed the outaged customers with the support of the DG. Operated in this mode, in contrast to the first mode, a DG is not necessarily placed in the circuit that has the smallest failure rate to obtain the maximum reliability benefit. An example of this is presented in the case study. There may be a short interruption to the customers not in the faulted zone. This is because the DG may need to be disconnected after the fault and then re-energized. In this paper, the third mode of operation is simulated.

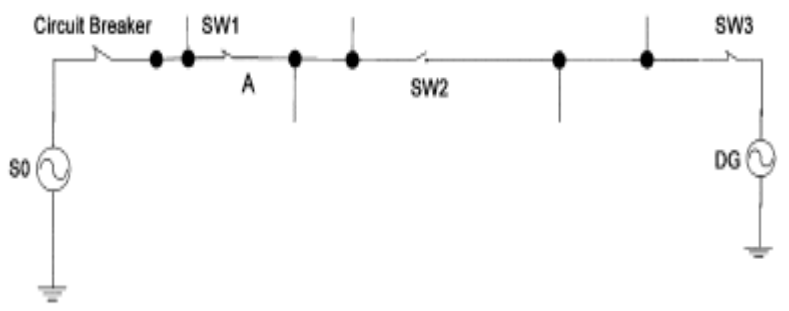

Fig. 2. DG island mode operation.

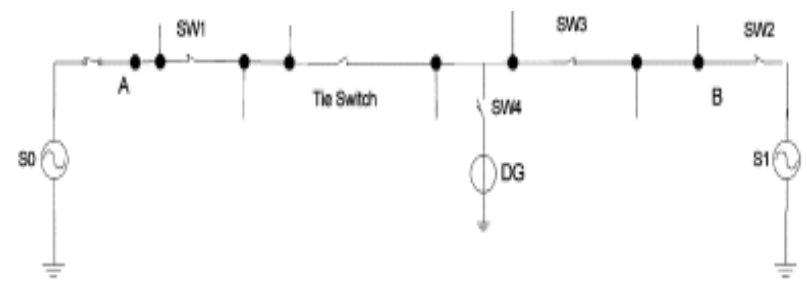

Fig. 3. DG with alternate feed.

\section{B. IMPACT OF DISTRIBUTED GENERATION ON DISTRIBUTION SYSTEM} RELIABILITY:

The DG connection to a distribution system helps to improve the reliability of the system. The use of the existing distribution system will be the best if DG is allocated optimally and if the development from passive to active is planned optimally with all relevant considerations taken into account. The reliability improvement will be maximum if the DG location provides maximum access to the customers in terms of customer numbers, overall demand and priority of customer. DG may be used as standby or backup source. Negative Impacts

- Increase in short circuit current

- Drop of sensitivity to faults

- Voltage rise and fluctuations

- Changes in losses and voltage Profile

- Frequency and voltage instability

Positive Impacts

- Voltage and reactive power Support

- Voltage control

- Reduction of losses and transmission blocking

- Generation growth and better utilization of assets

- Improvement of reliability by ensuring continuity of supply

V. GREY WOLF OPTIMIZER

This work proposes a new meta-heuristic called Grey Wolf Optimizer (GWO) inspired by grey wolves (Canis lupus). The GWO algorithm mimics leadership hierarchy and the 
chasing policy of gray wolves (Canis lupus). The gray wolf is a social animal, and they used to live in a pack of 5-12 members. The whole group can be categorized into four types of gray wolf, which are alpha $(\alpha)$, beta $(\beta)$, delta $(\delta)$, and omega $(\omega)$. Alpha holds the highest level in the social hierarchy of the pack, which decreases subsequently up to the omega. A pack of gray wolves can have a male or a female leader, called alpha. The alpha wolf dictates his or her decisions related to hunting, sleeping place, and so on to the pack, and the pack is bound to follow the alpha's decision. The betas, which can be males or females, are subordinate wolves to the alpha, and he or she is probably the best candidate, which replaces an alpha in case of death and aging of an alpha wolf. Betas are responsible for maintaining the discipline in the prey and reinforcing the commands of the alpha. At the same time, they give feedback to the alpha. Omega has the lowest rank in the gray wolf ranking. They are the last wolves that are allowed to eat. If a wolf is not an alpha, beta, or omega, he or she is called delta (or a subordinate wolf). Delta wolves dominate the omega, but they are lower to alphas and betas. Apart from the social hierarchy, another interesting social behavior of gray wolves is group hunting. They have a well-defined mechanism for hunting. At the very first, they approach the prey by means of tracking and chasing. After that, the pack of gray wolves encircles the prey and harasses it till the movement stop. After that, they attack towards the prey. The encircling behavior of the pack of gray wolves can be defined with the help of the following mathematical equations:

$\overrightarrow{\mathrm{D}}=|\overrightarrow{\mathrm{C}} \cdot \overrightarrow{\mathrm{Xp}}(\mathrm{t})-\overrightarrow{\mathrm{X}}(\mathrm{t})|$
$\overrightarrow{\mathrm{X}}(\mathrm{t}+1)=\overrightarrow{\mathrm{Xp}}(\mathrm{t})-\overrightarrow{\mathrm{A}} \cdot \overrightarrow{\mathrm{D}}$

Where $\overrightarrow{\mathrm{Xp}}$ is the position vector of the prey, while $\overrightarrow{\mathrm{X}}$ is the position vector of a gray wolf. ' $t$ ' indicates the current iteration, and $\vec{A}$ and $\vec{C}$ are the coefficient vectors, which can be calculated as follows:

$\overrightarrow{\mathrm{A}}=2 \overrightarrow{\mathrm{a}} \cdot \overrightarrow{\mathrm{r}}_{1}-\overrightarrow{\mathrm{a}}$

$\overrightarrow{\mathrm{C}}=2 \cdot \overrightarrow{\mathrm{r}}_{2}$

Where $\vec{r}_{1}$ and $\vec{r}_{2}$ are random vectors in [0,1], and components of $\vec{a}$ are linearly decreasing from 2 to 0 over the course of iterations. In the mathematical modeling of the hunting behavior of gray wolves, it is supposed that the alpha (best candidate solution), beta, and delta have better knowledge about the location of the prey. That is why we have saved the first three best solutions obtained so

far and oblige the other search agent, including omegas, to update their positions according to the position of the best search agents as per the following formulas:

$$
\begin{aligned}
& \overrightarrow{\mathrm{D}}_{\alpha}=\left|\overrightarrow{\mathrm{C}}_{1} \cdot \overrightarrow{\mathrm{X}}_{\mathrm{\alpha Q}}-\overrightarrow{\mathrm{X}}\right|, \quad \overrightarrow{\mathrm{D}}_{\beta}=\left|\overrightarrow{\mathrm{C}}_{2} \cdot \overrightarrow{\mathrm{X}}_{\beta}-\overrightarrow{\mathrm{X}}\right|, \overrightarrow{\mathrm{D}}_{0}=\left|\overrightarrow{\mathrm{C}}_{\mathrm{a}} \cdot \overrightarrow{\mathrm{X}}_{\mathrm{b}}-\overrightarrow{\mathrm{X}}\right| \\
& \overrightarrow{\mathrm{X}}_{1}=\overrightarrow{\mathrm{X}}_{\alpha}-\overrightarrow{\mathrm{A}}_{1} \cdot\left(\overrightarrow{\mathrm{D}}_{\alpha}\right), \overrightarrow{\mathrm{X}}_{2}=\overrightarrow{\mathrm{X}}_{\beta}-\overrightarrow{\mathrm{A}}_{2} \cdot\left(\overrightarrow{\mathrm{D}}_{\beta}\right), \overrightarrow{\mathrm{X}}_{\mathrm{a}}=\overrightarrow{\mathrm{X}}_{6}-\overrightarrow{\mathrm{A}}_{\mathrm{a}} \cdot\left(\overrightarrow{\mathrm{D}}_{6}\right) \\
& \overrightarrow{\mathrm{X}}(\mathrm{t}+1)=\frac{-\overrightarrow{\mathrm{X}}_{1}+\overrightarrow{\mathrm{X}}_{2}+\overrightarrow{\mathrm{X}}_{3}}{\mathrm{a}}
\end{aligned}
$$

In order to propagate exploration and exploitation, the parameter ' $a$ ' is decrease from 2 to 0 . Mathematically, $|\mathrm{A}|>1$ force the gray wolves to diverge from the prey in search of a fitter prey (exploration), while $|\mathrm{A}|<1$ force the wolves to attack towards the prey (exploitation) (Figures 4). 


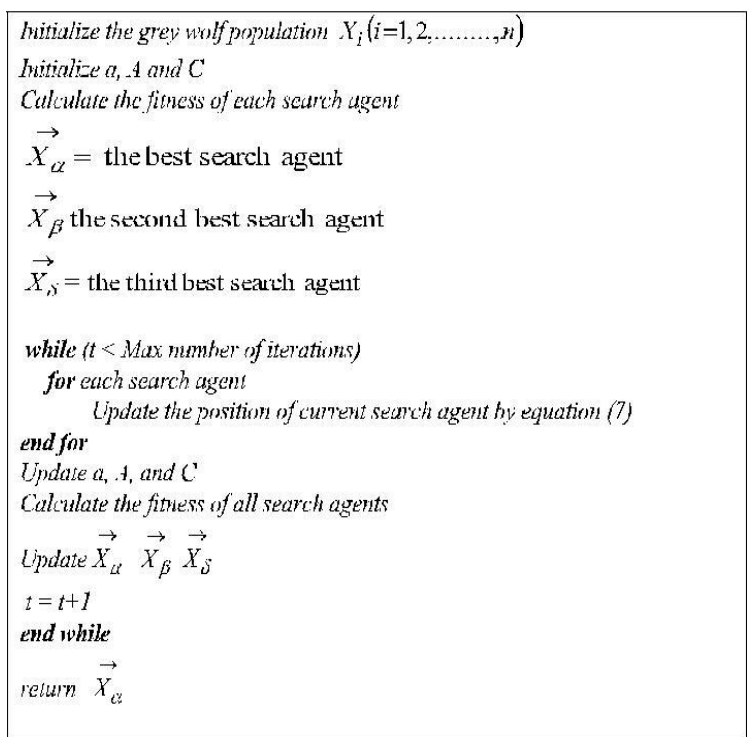

\section{CASE STUDIES}

Fig 4. Pseudo code of the gray wolf optimization algorithm

Three case studies are performed on the system.

A. Case 1

Case 1 assumes the system with no DG. The individual load point indices $(\lambda, r, U)$ are shown in [15]. Since the average demand and number of customers at each load point is known from [14],[16], the primary indices can be extended to give the customer- and load-oriented indices and they are shown in tables (1) shown below.

B. Case 2

Case 2 assumes the system with DGs.

The result indicates the greatest effect occurs for the load point furthest from supply point and nearest to the DG.

TABLE 1 . RELIABILITY OPTIMIZATION USING GWO ALGORITHM TO OPTIMIZE ENS

\begin{tabular}{|c|c|c|c|c|}
\hline & & ENS & AENS & DG location \\
\hline $\begin{array}{l}\bar{\Xi} \\
\text { U్ } \\
\text { U. }\end{array}$ & Without DG & 66612 & 3.9036 & -- \\
\hline \multirow{3}{*}{$\begin{array}{l}\text { N } \\
\tilde{z} \\
\tilde{z}\end{array}$} & With $\mathrm{DG}=30 \mathrm{KW}$ & 66035 & 3.8698 & At bus 49 \\
\hline & With DG=50 KW & 65650 & 3.8473 & At bus 61 \\
\hline & With DG=100 KW & 64688 & 3.7909 & At bus 50 \\
\hline
\end{tabular}

\section{CONCLUSIONS}

This paper attempts to improve the reliability of distribution systems. The effectiveness of the proposed objective functions has been investigated on a standard test distribution system showing promising results. The level of improvement depends on the type, number, size and position of the distributed generators. DG is being introduced into the traditional distribution network in order to enhance the power system reliability. The optimal placement of DGs is crucial for achieving such an objective. The reliability improvement is maximum if the DG is connected at a location from where it can meet the highest load demand. In this paper, an optimization procedure based on the GWO algorithm is developed to seek out the optimal DG location by minimizing ENS. The simulation results from the test distribution systems validate the effectiveness of the proposed method. 
OPTIMAL DG PLACEMENT IN A RADIAL DISTRIBUTION NETWORK FOR RELIABILITY IMPROVEMENT

\section{REFERENCES}

[1] L. W. L. Wang and C. Singh, "Reliability-Constrained Optimum Placement of Reclosers and Distributed Generators in Distribution Networks Using an Ant Colony System Algorithm," IEEE Trans. Syst. Man, Cybern. Part C (Applications Rev., vol. 38, no. 6, pp. 757-764, 2008.

[2] A. Kumar, S. Pant, and M. Ram, "System Reliability Optimization Using Gray Wolf Optimizer Algorithm," Qual. Reliab. Eng. Int., 2016.

[3] W. Tippachon and D. Rerkpreedapong, "Multiobjective optimal placement of switches and protective devices in electric power distribution systems using ant colony optimization," Electr. Power Syst. Res., vol. 79, no. 7, pp. 1171-1178, 2009.

[4] B. Das and B. Deka, "Impact of Distributed Generation on Reliability of Distribution System," IOSR Jounrla Electr. Electron. Eng., vol. 8, no. 1, pp. 4250, 2013.

[5] R. Billinton and R. Allan, Reliability Evaluation of Power Systems, vol. 2. 1996.

[6] R. Billinton, "A test system for teaching overall power system reliability assessment," IEEE Trans. Power Syst., vol. 11, no. 4, pp. 1670-1676, 1996.

[7] M. Hosseini, H. A. Shayanfar, and M. Fotuhi-Firuzabad, "Reliability improvement of distribution systems using SSVR," ISA Trans., vol. 48, no. 1, pp. 98-106, 2009.

[8] D. H. Popović, J. A. Greatbanks, M. Begović, and A. Pregelj, "Placement of distributed generators and reclosers for distribution network security and reliability," Int. J. Electr. Power Energy Syst., vol. 27, no. 5-6, pp. 398-408, 2005.

[9] A. Pregelj, M. Begović, and A. Rohatgi, "Recloser allocation for improved reliability of DG-enhanced distribution networks," IEEE Trans. Power Syst., vol. 21, no. 3, pp. 1442-1449, 2006.

[10] S. Ray, A. Bhattacharya, and S. Bhattacharjee, "Optimal placement of switches in a radial distribution network for reliability improvement," Int. J. Electr. Power Energy Syst., vol. 76, pp. 53-68, 2016.

[11] D. Zhu, R. P. Broadwater, K. S. Tam, R. Seguin, and H. Asgeirsson, "Impact of DG placement on reliability and efficiency with time-varying loads," IEEE Trans. Power Syst., vol. 21, no. 1, pp. 419-427, 2006.

[12] Y. M. Mao and K. N. Miu, "Switch placement to improve system reliability for radial distribution systems with distributed generation," Ieee Trans. Power Syst., vol. 18, no. 4, pp. 1346-1352, 2003.

[13] B. Das and B. Deka, "Impact of Location of Distributed Generation On Reliability of Distribution System," IOSR Jounrla Electr. Electron. Eng., vol. 8, no. 1, pp. 42-50, 2013.

[14] M. E. Baran and F. F. Wu, "Optimal capacitor placement on radial distribution systems," IEEE Trans. Power Deliv., vol. 4, no. 1, pp. 725-734, 1989.

[15] N. Gupta, A. Swarnkar, and K. R. Niazi, "Distribution network reconfiguration for power quality and reliability improvement using Genetic Algorithms," Int. J. Electr. Power Energy Syst., vol. 54, pp. 664-671, 2014.

[16] A. Kavousi-fard and T. Niknam, "Optimal Distribution Feeder Reconfiguration for Reliability Improvement Considering Uncertainty," Ieee Trans. Power Deliv., vol. 29, no. 3, pp. 1344-1353, 2014. 